\title{
(2) OPEN ACCESS \\ Illicit tobacco trade: empty pack survey in eight Argentinean cities
}

\author{
Maria Elisabet Pizarro 다, 'Gabriel Giacobone, ${ }^{1}$ Cinthia Shammah, ${ }^{1}$ \\ Michal Stoklosa (1) ${ }^{2}$
}

${ }^{1}$ FIC Argentina, CABA, Argentina ${ }^{2}$ Institute for Health Research and Policy, University of Illinois at Chicago, Chicago, Illinois, USA

\section{Correspondence to} Dr Maria Elisabet Pizarro, FIC Argentina, FIC Argentina, CABA (1425), Argentina; marita.pizarro@ficargentina.org

Received 5 December 2020 Revised 8 March 2021 Accepted 17 March 2021

\section{Check for updates}

(c) Author(s) (or their employer(s)) 2021. Re-use permitted under CC BY-NC. No commercial re-use. See rights and permissions. Published by BMJ.

To cite: Pizarro ME Giacobone G, Shammah C, et al. Tob Control Epub ahead of print: [please include Day Month Year]. doi:10.1136/ tobaccocontrol-2020-056405

\section{ABSTRACT}

Objective To estimate the prevalence of illicit tobacco trade (ITT) and different ITT modes_-tax stamp counterfeiting and smuggling - in Argentina.

Design Cross-sectional study using an empty tobacco pack survey with a simple random cluster sampling design. Classification as licit/illicit using forensic analysis of tax stamps and packs and econometric modelling. Setting Cities of Buenos Aires, La Matanza, Cordoba, Rosario, Mendoza, Neuquen, Posadas, Salta; JanuaryJune 2019.

Results Of a total sample of 15658 packs, $83.2 \%$ were manufactured in Argentina and $16.8 \%$ were foreign packs. Overall ITT prevalence-weighted by district population size — was estimated at $13.7 \%$, where $6.1 \%$ was attributable to stamp counterfeiting-that is, a forged stamp not issued by the national tax authorityand $7.6 \%$ to contraband smuggling of foreign cigarette packs - that is, illicit trade of packs across national borders.

Conclusions The ITT problem in Argentina seems to be equally represented by counterfeiting of tobacco tax stamps on packs with domestic features and smuggling of foreign cigarette packs. Foreign cigarettes represent a minor component of the pack sampled in most of the country, except in Salta and Posadas, which are located close to the border with Paraguay. It is essential to implement an effective track-and-trace system including the monitoring of tax stamp authenticity and increase border control to block the entry of smuggled products, particularly from Paraguay. Reducing ITT is necessary to ensure the effectiveness of tobacco taxation measures.

\section{INTRODUCTION}

Tobacco tax policies are very effective to reduce tobacco consumption and prevent smoking initiation. ${ }^{12}$ This is also why the tobacco industry lobbies aggressively against such measures, based on the claim that tobacco taxation fosters illicit tobacco trade (ITT). ${ }^{34}$

Although Argentina has not ratified the Framework Convention for Tobacco Control (FCTC), significant progress has been made in terms of policies to curb the tobacco epidemic over the past 10 years. $^{5}$ One of such policies ${ }^{6}$ raised excise taxes on tobacco from 60\% to 75\% in May 2016. In December 2017, Act 27430 reduced this tax from $75 \%$ to $70 \%$, but also established a tax floor of AR $\$ 28$ per pack (about US\$1.2 at the time) adjusted by the Consumer Price Index. ${ }^{5}$ This policy had uneven effects, enabling lower prices for the more expensive brands but increasing the cost of economy products. ${ }^{7}$ A study commissioned by the tobacco industry and conducted by a market research consultant claimed that the new law would lead to an increase in illicit cigarette trade from $14 \%$ to $22 \%$ of the market following the policy's entry into force in March 2018. This study was used by the industry as grounds to protest the legislation. ${ }^{7}$ Moreover, national tobacco manufacturers, who focus on low-cost cigarettes, filed an injunction (still in force as of February 2021) to prevent the application of this tax floor that would make their products less affordable. Although it has been suggested that the prevalence of ITT in the Latin American region could be one of the highest worldwide, ${ }^{8}$ there is a growing body of evidence suggesting that the tobacco industry grossly overestimates ITT, ${ }^{9-13}$ including in Latin American countries such as Colombia, ${ }^{14}$ Chile $^{15}$ and Mexico. ${ }^{16}$

Argentina has procedures in place to control illicit trade practices, such as the TRAFIP track-and-trace system launched in 2010 by the country's internal revenue service, AFIP (Administración Federal de Ingresos Públicos). ${ }^{17}$ TRAFIP aims to control compliance with excise tax on the production and import of tobacco and other products and includes the printing and distribution of stamps certifying that these products have complied with applicable excise/import/export tax policies.

Until recently, there were little industryindependent data to assess the prevalence of ITT and the effectiveness of TRAFIP in Argentina. A recent global review of illicit trade in a variety of products was funded by the tobacco industry, among others. ${ }^{18}$ In its 2018 report, Euromonitor estimated that illicit cigarettes accounted for $12.4 \%$ of the national market, ${ }^{19}$ but the main source of trade data for Euromonitor is the tobacco industry and their reports have been known to present inconsistencies. $^{20}$ Moreover, Euromonitor was contracted by Philip Morris International (PMI) Impact and the PMI-funded Foundation for a Smoke-Free World in 2019 , casting serious doubt on their independence. ${ }^{21}$ A review of expert opinions on ITT conducted by Ramos in 2009 estimated that smuggling accounted for $7 \%-12 \%$ of the total consumption of cigarettes in Argentina, but the reliability of this estimation is unclear. ${ }^{22}$ In turn, Paraje applied gap analysis to estimate trends in ITT, concluding that these practices had remained stable from 2009 on, ${ }^{23}$ but the actual prevalence of illicit practices in tobacco trade remained unknown. One of the challenges for gap analysis in Argentina is that tobacco consumption might be under-reported. Besides, there is a general lack of reliable data. For example, the National Risk Factor Survey provides cigarette consumption data 
for adults only, ${ }^{24}$ and accounting for youth consumption could be problematic. Similarly, the tax-paid data might be incomplete. Finally, the gap analysis fails to account for the possibility that some of the tax-paid domestic cigarettes are being smuggled to the neighbouring Chile. In view of these limitations, in the ITT estimation conducted by González-Rozada using gap analysis, the author performed various sensitivity analyses to estimate ITT. ${ }^{25}$ However, the ITT levels estimated by this study were extremely high (from $36 \%$ to $46 \%$ of the market), a likely outcome of the above-mentioned shortcomings of the gap analysis.

An alternative method to gap analysis is empty pack surveys (EPS), which have been successful to estimate tax avoidance and ITT practices in other settings. ${ }^{10-12} 162627$ To contribute to the generation of independent data on ITT, FIC Argentina conducted a pilot EPS restricted to the City of Buenos Aires (CABA) to assess the prevalence of ITT practices in March-April 2018, which was estimated at approximately 4\%. The main form of ITT documented was tax evasion via stamp counterfeiting (FIC Argentina, 2020). Despite its restricted geographical setting, this study was useful to test the methodology in Argentina and to bring attention to the deficiencies of the TRAFIP in keeping track of cigarette production, distribution and consumption.

The overall purpose of this study was to estimate the prevalence of ITT in the country a little over a year after the implementation of the tobacco tax regulations mentioned above (December 2017) by extending the EPS methodology tested in CABA to other urban districts. The selected districts represent diverse socioeconomic, cultural and geographical settings, which could facilitate the observation of other modes of ITT (eg, smuggling) that may be more frequent in other jurisdictions. An additional specific objective was to assess whether the situation of ITT had changed between 2018 and 2019 in CABA.

\section{METHODOLOGY}

This was a cross-sectional study conducted in January-June 2019 in eight densely populated localities in Argentina, including CABA, Argentina's capital and home to nearly 3 million people. Rosario (province of Santa Fe), Córdoba (province of Córdoba) and La Matanza (province of Buenos Aires) are the three most populated urban districts in the country, after CABA. Mendoza (province of Mendoza), Neuquen (province of Neuquen), Salta (province of Salta) and Posadas (province of Misiones) are provincial capitals located close to the country's western and northern borders (figure 1). Together, these districts are home to approximately $19 \%$ of the total Argentinean population. ${ }^{28}$

\section{Sample size and design}

This study employed a one-stage cluster design, selecting a random sample of census fractions-that is, geographically bound areas that include an average of 5000 householdsfor each district, to ensure a minimum coverage of $50 \%$ of all fractions.

The pilot study conducted in CABA in 2018 found that the prevalence of ITT was approximately 4\% (95\% CI: 3\% to 5\%), meaning that $\sim 4 \%$ of the collected packs were classified as illicit. Based on this data, we calculated a minimum sample size of 1080 20-cigarette packs and 480 smaller packs per district to estimate ITT prevalence with a 95\% level of confidence.

\section{Fieldwork: collection of empty packs}

A trained collector was instructed to recover every discarded cigarette pack along a route starting at the centre of each selected fraction and walking around four city blocks (400 $\mathrm{m}$ in perimeter

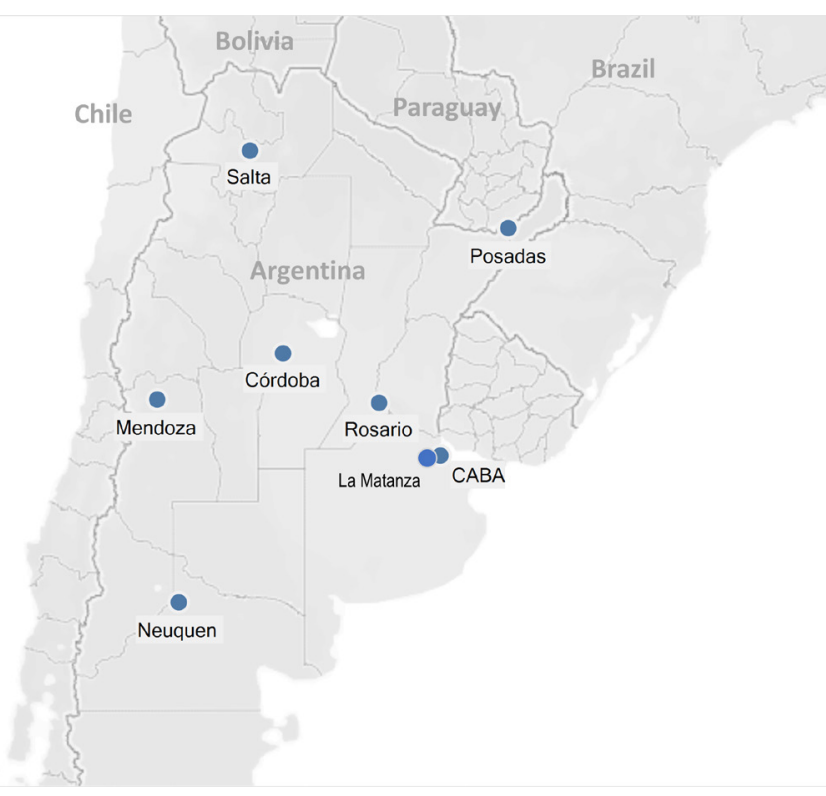

Figure 1 Location of the eight Argentinean cities included in the study.

each) following a 'flower' pattern. The end-result was a twoby-two grid of $400 \mathrm{~m}^{2} /$ city blocks for each collection route. If the packs collected along this route did not meet minimum sample size requirements, the process was repeated along another similar route within the same fraction. The street surface and garbage disposal units were not included for safety reasons. This study focused exclusively on cigarettes, the product used by most tobacco consumers $(90 \%){ }^{19}$

\section{Data collection: classification of packs as licit/illicit}

The unit of analysis was each cigarette pack. For the purposes of this study, packs were considered illicit if not all applicable domestic taxes had been paid on them. This includes packs with domestic features with counterfeit tax stamps and packs which entered the country illegally, that is, smuggling current regulations $^{29}$ prescribe blue stamps for domestic 20-cigarette packs, green stamps for 10-cigarette packs and purple stamps for other presentations. Legally imported cigarettes must display a red tax stamp in all presentations and sizes. AFIP prints and distributes these stamps to legal cigarette manufacturers and importers.

The method followed to classify packs as licit/illicit presented in detail below was developed and tested in a pilot study conducted in 2018 in CABA.

\section{Forensic analysis of tax stamps and pack features}

Packs with domestic features (from here on, 'domestic packs') were considered as licit if (a) the brand was registered for legal sale in Argentina ('brand legitimacy'), (b) the pack carried the mandatory health warnings issued by the National Ministry of Health in 2016 ('warning legitimacy') and (c) it carried an authentic tax stamp. Stamp authenticity was evaluated by a forensic expert, determined by observation under ultraviolet light with a linen tester $(\times 5)$ and a cutting instrument, in view of the tax stamp specifications in AFIP regulations ${ }^{29}$ and by comparison with an undoubtedly authentic stamp. A second level of analysis was performed on packs that did not include a tax stamp. Because stamps are attached to the packs using an adhesive, they are very easily removed or torn. In these cases, the expert analysed brand and pack attributes (paper type, 
Quick Response (QR) code, print and format type) compared with an original, undoubtedly licit pack. If these attributes were as expected from observation of the original, an econometric model was used to estimate the probability of the pack having an illicit origin.

\section{Econometric modelling}

When cigarette packs did not carry a tax stamp suitable for forensic analysis and there were no other indicators of ITT as detailed above ('undetermined' packs), an econometric model was used to estimate the likelihood of a pack having an illicit origin. A logistic regression model was employed due to the binary nature of ITT (licit vs not licit). Based on the results of the tax stamp analysis conducted on the collected packs, the pack features that could best predict pack licitness were identified and used as explanatory variables in the model. Over 95\% of the packs classified as illicit by stamp analysis were economy brands, which suggested that market segment (economy, standard, premium) was a strong predictor of ITT in domestic packs. Another relevant variable was pack size, since counterfeit stamps were mostly found in 20-unit packs. Therefore, the likelihood of ITT for the 1924 packs that did not carry tax stamps was estimated using logistic regression with market segment and pack size as explanatory variables, as per the model:

$$
\log \left(\frac{\mathrm{P}_{\mathrm{ITT}}}{1-\mathrm{P}_{\mathrm{ITT}}}\right)=\beta_{\mathrm{O}}+\beta_{1} \text { Segment }+\beta_{2} \text { Size }
$$

Where the dependent variable ITT was coded as $1=$ illicit $/ 0=$ licit, the pack size was coded as $1=20$-unit pack $/ 0=$ smaller packs, and market segment was coded as $2=$ economy $/ 1=$ standard $/ 0=$ premium.

Using this model, the probability of ITT was calculated for each of the undetermined packs and the number of illicit packs in the undetermined pack sample was calculated as the mean estimated ITT probability multiplied by the undetermined sample size.

In foreign packs, the absence of a red tax stamp could also be due to factors other than smuggling, since the stamp may have fallen off or the pack could have been entered legally into the country by foreign visitors for personal use. However, unlike domestic ones, there is no available frame of reference to develop a reliable econometric model for foreign packs. Therefore, all foreign packs with no red tax stamps were classified as illicit, so smuggling is probably overestimated. Our results should be considered maximum estimates for the prevalence of smuggling in Argentina.

\section{Data analysis}

Cigarette packs were categorised according to market segments (premium, standard and economy brands) and presentations (20, 15, 12 and 10-cigarette packs). Premium (US\$2 average price) and standard brands (US\$1.5) are manufactured in Argentina by transnational companies. During the first semester of 2019 , premium and standard brands accounted for $56 \%$ and $31 \%$ of total cigarette sales. In turn, economy brands (US $\$ 0.83$ average price) are commercialised by national tobacco companies and represented $13 \%$ of total cigarette sales. ${ }^{30}$

The prevalence of ITT was estimated as the proportion of illicit packs over category totals (point and 95\% CI estimates) and overall totals weighted by locality population size. Comparison of 2018 and 2019 estimates from CABA was realised via a standard t-test of difference in means. These analyses and the logistic regression model were performed using Stata MP V.13 software.

\section{RESULTS}

\section{Overview}

A detailed description of the sample by locality can be consulted in table 1. A total of 15658 packs were collected in the eight districts, ranging between 1596 in Neuquén and 2116 in La Matanza. Of the total sample, 10074 (64.3\%) were 20-cigarette packs and $5584(35.7 \%)$ were smaller presentations. Argentinean brands represented approximately $83 \%$ of the total sample $(n=13$ 027), of which most belonged to premium brands ( $\mathrm{n}=9131)$, followed by standard $(\mathrm{n}=2147)$ and economy $(n=1749)$ brands. Posadas and Salta, which are located close to

Table 1 Frequency distribution of the cigarette pack sample by origin, size and market segment in each locality; Argentina, 2019

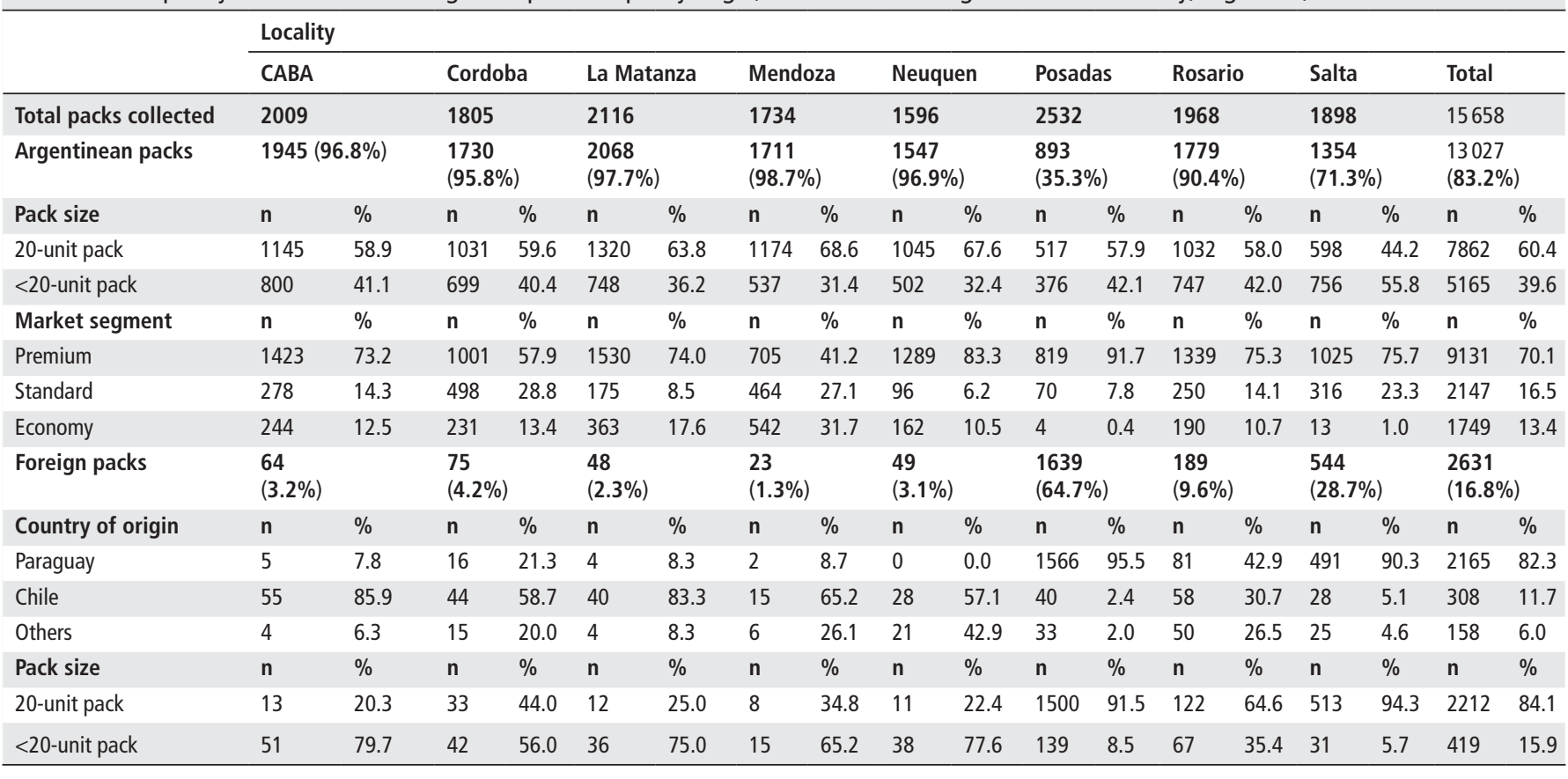


Table 2 Prevalence of illicit tobacco trade (ITT) by locality and by mode: counterfeit tax stamps in packs manufactured in Argentina determined by stamp analysis or econometric modelling and smuggling of foreign packs

\begin{tabular}{|c|c|c|c|c|c|c|c|c|c|c|}
\hline & \multicolumn{10}{|c|}{ Counterfeiting (domestic packs) } \\
\hline & \multicolumn{3}{|c|}{$\begin{array}{l}\text { Expert analysis of tax stamps/pack } \\
\text { features }\end{array}$} & \multicolumn{3}{|c|}{$\begin{array}{l}\text { Combined stamp analysis+econometric } \\
\text { model }\end{array}$} & \multicolumn{3}{|c|}{ Smuggling (foreign packs) } & \multirow[b]{2}{*}{ Overall ITT (\%) } \\
\hline & Total (n) & Counterfeit (\%) & $95 \% \mathrm{Cl}$ & Total (n) & Counterfeit (\%) & $95 \% \mathrm{Cl}$ & Total (n) & Smuggling (\%) & $95 \% \mathrm{Cl}$ & \\
\hline CABA & 1658 & 4.4 & 3.4 to 5.3 & 1945 & 5.8 & 5.1 to 6.5 & 64 & 12.5 & 4.3 to 21.5 & 6.1 \\
\hline Córdoba & 1512 & 5.3 & 4.1 to 6.4 & 1730 & 6.1 & 5.4 to 6.8 & 75 & 41.3 & 31.3 to 54.8 & 7.7 \\
\hline La Matanza & 1741 & 4.8 & 3.7 to 5.7 & 2068 & 7.9 & 7.2 to 8.6 & 48 & 8.3 & 0.2 to 17.9 & 7.9 \\
\hline Mendoza & 1464 & 17.6 & 15.6 to 19.5 & 1711 & 14.0 & 13.2 to 15.1 & 23 & 34.7 & 13.7 to 55.8 & 14.5 \\
\hline Neuquén & 1330 & 4.4 & 3.3 to 5.5 & 1547 & 4.8 & 4.1 to 5.4 & 49 & 0.0 & 0.0 to 0.0 & 4.7 \\
\hline Posadas & 833 & 0.5 & 0.0 to 0.1 & 893 & 0.5 & 0.2 to 0.6 & 1639 & 98.7 & 98.2 to 99.3 & 64.1 \\
\hline Rosario & 1500 & 5.5 & 4.3 to 6.6 & 1779 & 5.3 & 4.5 to 6.0 & 189 & 60.3 & 54.2 to 68.4 & 10.9 \\
\hline Salta & 1065 & 0.5 & 0.0 to 0.1 & 1354 & 0.6 & 0.3 to 0.8 & 544 & 94.1 & 92.3 to 96.2 & 27.7 \\
\hline Total & 11103 & $5.8^{*}$ & 5.3 to 6.2 & 13027 & $6.1^{*}$ & 5.9 to 6.4 & 2631 & $7.6^{*}$ & 7.2 to 8.0 & $13.7^{*}$ \\
\hline
\end{tabular}

*Weighted by population size per locality.

the border with Paraguay, presented high proportions-61.8\% and $25.9 \%$, respectively-of cigarettes manufactured in this neighbour country, while foreign cigarettes contributed less than $10 \%$ to the samples of all other localities. Most of the foreign packs (82.4\%) in the overall sample were manufactured in Paraguay. However, packs manufactured in Chile dominated the foreign pack sample in CABA, Cordoba, La Matanza, Mendoza and Neuquen, where foreign packs represented less than $5 \%$ of the total.

Overall ITT prevalence was estimated at $13.7 \%$, where $6.1 \%$ was attributable to stamp counterfeiting and $7.6 \%$ to smuggling (table 2). Figure 2 illustrates the study work flow and summarises the results of the overall sample classification (licit vs illicit packs) as detailed in the following sections. The cities of Posadas and Salta, located close to the northern country border, presented extremely high prevalence of ITT $(64.1 \%$ and $27.7 \%$, respectively) mainly due to smuggling, while Mendoza showed a high proportion of packs with counterfeit tax stamps (14.0\%).

\section{Packs manufactured in-country: forensic analysis of tax stamps}

Of the 13027 packs manufactured in Argentina, 11094 (85.2\%) carried a tax stamp, making them amenable to forensic analysis of tax stamp authenticity, which determined that 644 of them were counterfeit. Of the packs that did not carry a tax stamp, nine were considered to have pack features that did not match undoubtedly licit packs (eg, type of paper, print format, QR code). Based on this analysis alone, the prevalence of ITT in the form of tax stamp counterfeiting was estimated at 5.8\% (95\% CI: $5.3 \%$ to $6.2 \%$ ). The percentage of counterfeit stamps in Mendoza nearly tripled the overall national prevalence $(17.6 \%$, 95\% CI: $15.6 \%$ to $19.5 \%$ ) (table 2 ).

Of the total counterfeit stamps, 95.4\% $(n=585)$ belonged to economy brand packs, while only $3.3 \%(n=20)$ and $1.3 \%(n=8)$ were present in premium and standard brands, respectively. The prevalence of stamp counterfeiting was highest among economy brands (44.0\%, 95\% CI: $41.3 \%$ to $46.7 \%)$ and negligible among

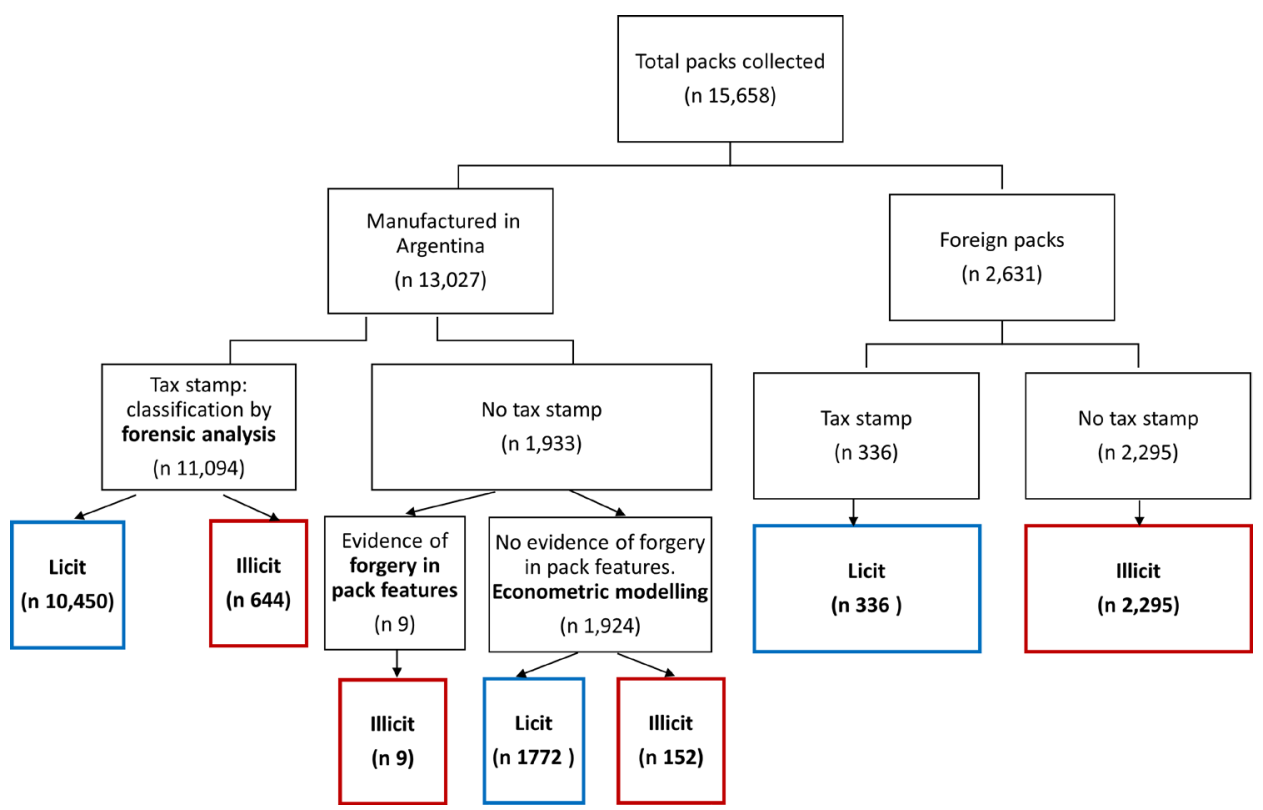

Figure 2 Schematic representation of empty cigarette pack classification as licit or illicit. 
Table 3 Logistic regression model predicting probability of a cigarette pack being illicit; Argentina, 2019

\begin{tabular}{lllcll}
\hline & OR & SE & \multicolumn{1}{l}{$\mathbf{z}$} & $\mathbf{P}>|\mathbf{z}|$ & $95 \% \mathrm{Cl}$ \\
\hline Pack size & 2.26738 & 0.94320 & 1.97 & 0.049 & 1.00332 to 5.12403 \\
Segment & & & & & \\
$\quad$ Standard & 1.71238 & 0.717912 & 1.28 & 0.200 & 0.75289 to 3.89464 \\
Economy & 240.8542 & 61.9259 & 21.33 & 0.000 & 145.5131 to 398.6631 \\
cons & 0.00151 & 0.00057 & 0.000 & 0.000 & 0.00072 to 0.00316 \\
\hline
\end{tabular}

premium $(0.3 \%, 95 \%$ CI: $0.1 \%$ to $0.4 \%)$ and standard brands $(0.1 \%$ to $0.7 \%)$.

The sample of packs that carried a tax stamp was divided into three pack sizes: $20(n=6522), 11(n=798)$ and 10 cigarettes $(n=3613)$. Counterfeit stamps were present in $9.5 \%$ of 20-cigarette packs (95\% CI: $9.9 \%$ to $10.4 \%$ ), while a very low prevalence was found in 10 -cigarette $(0.1 \%, 95 \% \mathrm{CI}: 0.0 \%$ to $0.3 \%)$ and 11 -cigarette packs $(0.2 \%, 95 \% \mathrm{CI}: 0.0 \%$ to $0.6 \%)$.

\section{Econometric modelling}

The total pack sample included 1924 packs that did not carry a tax stamp and had no other indicators of ITT ('undetermined' packs). The number of illicit packs in this sample was estimated using logistic regression with market segment (economy, standard, premium) and pack size (20-unit packs vs smaller packs) as explanatory variables.

The model was significant overall (likelihood ratio $\left.\chi_{(6)}^{2}=2702.1 ; p=0.000\right)$ with a medium goodness of fit (pseudo- $\mathrm{R}^{2}=0.55$ ) (table 3 ). No significant differences were found between standard and premium segments, but economy packs were estimated to be over 200 times more likely to be illicit than premium packs, while 20 -unit packs were over twice more likely to be illicit than smaller presentations. This analysis determined that out of the 1924 undetermined packs, 152 were likely to be illicit.

Combining the results of stamp analysis and econometric modelling and weighing the contribution of each district by population size, overall ITT prevalence in domestic packs was estimated to be $6.2 \%$, with Mendoza presenting the highest value (14.2\%) and Posadas the lowest, at $0.5 \%$ (table 2).

\section{Illicit import of foreign cigarette packs}

Of the total pack sample, $16.8 \%(n=2631)$ corresponded to foreign brands, of which $87 \%(n=2295)$ did not carry the red stamp that certifies the payment of import duties. In districts where foreign cigarette packs were particularly frequent, such as Posadas and Salta, the proportions of packs without red stamps were also extremely high: $98.7 \%$ and $94.1 \%$, respectively (table 2). Tax stamps were absent in most of the 20-cigarette (98.0\% out of a total of 2211 packs) and 10-cigarette packs (95.9\% of 122), but they were present in most 11-cigarette and 12-cigarette packs (90.0\% and 97.6\%, respectively). Most foreign packs without tax stamps (94\%) were manufactured in Paraguay.

\section{CABA: 2018 vs 2019 results}

In 2018 , a pilot study was conducted to test this methodology in Argentina, limited to CABA. This study focused on 20-unit cigarette domestic packs using forensic determination of tax stamp authenticity and econometric modelling (FIC Argentina, 2020). The prevalence of ITT in 2018 was estimated at 3.9\% (95\% CI: $3.3 \%$ to $4.4 \%$ ). In this study, the prevalence of ITT in 20-unit domestic packs in CABA was 7.5\% (95\% CI: $5.9 \%$ to $9.2 \%$ ), meaning that ITT prevalence in this pack size increased from 2018 to 2019 (difference $=3.6 \%, 95 \%$ CI: $2.2 \%$ to $5.1 \%, \mathrm{t}_{(5348)}$ : $4.98, \mathrm{p}<0.01)$. Statistical analysis of imported packs was not possible due to small sample sizes.

\section{DISCUSSION}

In this study we have estimated overall ITT at $13.7 \%$, with similar contributions of stamp counterfeiting and smuggling. These results are consistent with some of the trends detected in the CABA pilot study in 2018. While evidence of stamp counterfeiting was found in nearly $6 \%$ of the overall sample and $10 \%$ of the 20 -cigarette pack sample, most of these packs (95\%) belonged to economy brands. Stamp counterfeiting was particularly frequent in the city of Mendoza (14\%), which lends some support to tobacco industry claims regarding the high prevalence of brand abuse in this province. ${ }^{31}$ This merits further research, since we do not currently have any evidence that could potentially explain this phenomenon. Although the prevalence of stamp counterfeiting doubled in CABA from 2018 to 2019, its probable cause is the proportion of economy brands in the sample, which was $12 \%$ in 2018 , but almost $20.8 \%$ in 2019 . In a smokers' survey conducted in 2019, many respondents reported having switched to less expensive cigarette brands. ${ }^{32}$ While Argentina's high inflation rates and falling purchasing power of salaries could potentially explain this switch to lower cost brands, the injunction filed by national tobacco manufacturers preventing application of the legal tax floor and keeping prices low for economy products has definitely facilitated the switch, undermining the effectiveness of tobacco control price policies.

As for foreign packs, over $80 \%$ did not carry the red stamp that certifies compliance with import tax policies. Due to the lack of a suitable frame of reference to estimate the likelihood of foreign packs being illicit, there was no way to reliably distinguish between licit and illicit non-domestic products when the red tax stamp was missing because some of these non-domestic packs could have been brought to Argentina legally. Therefore, the $\sim 8 \%$ estimate presented here should be considered as a maximum value for the prevalence of smuggling nationwide. However, a strong case can be made that these packs were indeed smuggled to Argentina, particularly in Posadas and Salta, which are located close to the northern Argentinean border. In these cities, foreign packs composed of a significant part of the total sample (65\% and 29\%), and most of them did not carry the stamp (98\% and 94\%). Paraguay was the country of origin of most of these packs, a country whose role as a regional supplier of illicit, low-price brands, has been well established in the literature. ${ }^{8} 2733$ Moreover, data provided by the national security forces indicate that Paraguayan brands were the most frequently confiscated at border and domestic checkpoints in these northern Argentinean provinces in 2019, while Paraguayan packs without red tax stamps were available for purchase in many legal pointsof-sale in Posadas and Salta (FIC Argentina, 2020).

These findings have significant implications for tobacco control in Argentina and the Latin America and the Caribbean region. Today, Big Tobacco is funding governmental initiatives to reduce tobacco ITT in the country. ${ }^{34} 35$ ITT is a significant problem that must be addressed, but the tobacco industry should be strictly excluded from the decision-making process involved in the design and implementation of these policies. The claim that increasing taxes would raise tobacco ITT to $22 \%$ of the market is not supported by the evidence. Moreover, if the estimates provided by Ramos 22 in 2009 were accurate, it would 
mean that smuggling has remained stable or even decreased over the past 10 years, despite increasing tobacco taxes, a trend that has also been described in Chile, Colombia and Peru. ${ }^{23}$

Another implication is that controls and track-and-trace measures currently in place, such as TRAFIP, are insufficient to reduce ITT practices in Argentina. TRAFIP's main objective is to minimise illicit trade practices of specific products by distributing security prints enabling identification and tracking of legally traded products. ${ }^{17}$ However, the resolution does not include any specification on how the system should be implemented and controlled, nor are there any publicly available indicators of the system's performance and effectiveness in preventing these illicit practices.

In this context, it is critical that the country ratifies the FCTC and implements the WHO Protocol to Eliminate Illicit Trade in Tobacco Products, ${ }^{36}$ which has specific requirements to improve traceability of tobacco products, increase tobacco industry accountability and strengthen international cooperation. Argentina's ratification of the FCTC is essential not only to address local tobacco control issues but also to enable the country to pressure other Southern Common Market (MERCOSUR) countries to do the same. Paraguay is one of the main countries of origin for illicit cigarettes worldwide, ${ }^{83}$ and though the country has ratified the FCTC, it has yet to become a party to the Protocol to Eliminate Illicit Trade in Tobacco Products. Paraguay's ratification and effective implementation of the protocol is critical to tackle the problem of ITT in MERCOSUR. Although the MERCOSUR parties Argentina, Brazil, Paraguay and Uruguay signed an agreement in December 2004 to address ITT, ${ }^{22}$ over 15 years later these countries have failed to develop coordinated initiatives to curb smuggling. To describe just one example, the $3400 \mathrm{~km}$ long 'Hydro-way' formed by the Paraguay, Parana and Uruguay rivers is one of the main causeways for MERCOSUR international trade, both licit and illicit. According to state department sources, 'Mercosur countries and Bolivia have been trying to close this deal for over 10 years [...] But Paraguay and Bolivia continue to raise objections ${ }^{37}$ (translation by the authors). ${ }^{83}$

\section{What this paper adds}

- Estimations of illicit tobacco trade (ITT) that are independent of tobacco industry-reported data are very scarce worldwide and particularly in Latin America.

- Industry-independent estimates of ITT are critical for public health because the tobacco industry is known to exaggerate ITT prevalence to oppose effective tobacco control legislation, such as tax policies.

- Using a rigorous empty pack survey methodology to estimate the prevalence of ITT in eight of the largest cities in Argentina, our study suggests that overall ITT prevalence was $13.7 \%$, where $6.1 \%$ was attributable to stamp forgery of domestic cigarette packs and $7.6 \%$ to smuggling of foreign packs.

- The prevalence of smuggling was unevenly distributed throughout the country, which can be partly explained by relative proximity of different cities to the border with Paraguay, a known hub of ITT.

- Tax stamp counterfeiting was mostly prevalent among economy brands, which reduces the effectiveness of tobacco tax increase policies in reducing smoking-related illness, particularly among the less affluent.
One of the main strengths of this study is its analysis based on tax stamp authenticity. Without this technique, the prevalence of stamp counterfeiting in Argentina would have been underestimated by EPS. The sample design ensured high coverage of sampled districts and large sample sizes, with a wide geographical scope, despite excluding rural settings and smaller cities. Perhaps its most significant limitation was the indeterminate nature of foreign packs that do not carry a tax stamp. While we consider the assumption that these packs were product of smuggling to be well grounded, as described above, developing frames of reference and/or models to generate accurate estimates of ITT in foreign packs might prove a significant area for future research.

Argentina reduced its tobacco smoking prevalence by more than half from 2000 to 2020. Illicit tobacco trade is threatening this progress by making cigarettes more available and affordable. This study provides valuable information for policymakers and law enforcement in the region by estimating the scope of the illicit cigarette trade nationwide and bringing to light the inadequacy of the current track-and-trace system. Effective measures to curb illicit trade in Argentina without tobacco industry interference will advance public health and increase much-needed government revenue.

Acknowledgements The authors thank Fernanda Báez, Blanca Giménez Prieto, Erica Labegueríe, Maga Merlo Vijarra, Liliana Rateni, Ernesto Ruiz and Tomas Smith for their assistance in coordinating the fieldwork, as well as FIC Argentina's and American Cancer Society's staff for their ongoing encouragement and support. They also appreciate Malena Pirola's help in drafting the manuscript and the suggestions made by the three anonymous peer reviewers, which have greatly improved this paper.

Contributors MEP devised and supervised the study and led data analysis and interpretation. GG designed the methodology and conducted the data analysis. GG and CS coordinated fieldwork and data collection. MS provided methodological advice. All authors participated in drafting and revising the manuscript.

Funding This study was funded by the American Cancer Society (ACS) under grant \#40971.

Disclaimer The content is solely the responsibility of the authors and does not necessarily represent the views of the ACS.

Map disclaimer The depiction of boundaries on this map does not imply the expression of any opinion whatsoever on the part of BMJ (or any member of its group) concerning the legal status of any country, territory, jurisdiction or area or of its authorities. This map is provided without any warranty of any kind, either express or implied.

Competing interests None declared.

Patient consent for publication Not required.

Provenance and peer review Not commissioned; externally peer reviewed.

Data availability statement Data are available upon reasonable request.

Open access This is an open access article distributed in accordance with the Creative Commons Attribution Non Commercial (CC BY-NC 4.0) license, which permits others to distribute, remix, adapt, build upon this work non-commercially, and license their derivative works on different terms, provided the original work is properly cited, appropriate credit is given, any changes made indicated, and the use is non-commercial. See: http://creativecommons.org/licenses/by-nc/4.0/.

\section{ORCID iDs}

Maria Elisabet Pizarro http://orcid.org/0000-0003-0626-8596

Michal Stoklosa http://orcid.org/0000-0003-2014-539X

\section{REFERENCES}

1 Drope J, Schluger N, Cahn Z. The tobacco atlas. Atlanta: American Cancer Society and Vital Strategies, 2018.

2 World Health Organization. Report on the global tobacco epidemic: the MPOWER package. Geneva: World Health Organization, 2008.

3 Joossens L, Raw M. Cigarette smuggling in Europe: who really benefits? Tob Control 1998;7:66-71. 
4 Transnational Alliance to Combat Illicit Trade (TRACIT). Media release: Latin America scores low on illicit trade index. must do more to tackle illicit trade. Available: https:// www.tracit.org/uploads/1/0/2/2/102238034/tracit_press_release_came.final.pdf [Accessed 9 Sep 2020].

5 Pizarro ME, Rodríguez-Iglesias G, Gutkowski P, et al. Avances en impuestos del tabaco: El caso de Argentina. Rev Panam Salud Publica 2018;42:e46.

6 Regulation: Decreto 626/2016 del Poder Ejecutivo Nacional. Impuestos Internos, 2016. Available: http://servicios.infoleg.gob.ar/infoleglnternet/verNorma.do?id= 260938 [Accessed 18 Jul 2016].

7 Nacion L. La reforma tributaria abrió Una grieta entre LAS empresas tabacaleras, 2018. Available: https://www.lanacion.com.ar/economia/la-reforma-tributaria-abriouna-grieta-entre-las-empresas-tabacaleras-nid2090778 [Accessed 28 Oct 2019].

8 Iglesias RM, Gomis B, Carrillo Botero N, Botero NC, et al. From transit hub to major supplier of illicit cigarettes to Argentina and Brazil: the changing role of domestic production and transnational tobacco companies in Paraguay between 1960 and 2003. Global Health 2018;14:111.

9 Merriman D. The micro-geography of Tax avoidance: evidence from littered cigarette packs in Chicago. Am Econ J Econ Policy 2010;2:61-84.

10 Barker DC, Wang S, Merriman D, et al. Estimating cigarette Tax avoidance and evasion: evidence from a national sample of littered packs. Tob Control 2016;25:i38-43.

11 Stoklosa M, Ross H. Contrasting academic and tobacco industry estimates of illicit cigarette trade: evidence from Warsaw, Poland. Tob Control 2014;23:e30-4.

12 Kurti MK, von Lampe K, Thompkins DE. The illegal cigarette market in a socioeconomically deprived inner-city area: the case of the South Bronx. Tob Control 2013;22:138-40.

13 Gallagher AWA, Evans-Reeves KA, Hatchard JL, et al. Tobacco industry data on illicit tobacco trade: a systematic review of existing assessments. Tob Control 2019;28:334-45.

14 Maldonado N, Llorente B, Escobar D, et al. Smoke signals: monitoring illicit cigarettes and smoking behaviour in Colombia to support tobacco taxes. Tob Control 2020;29:s243-8.

15 Paraje G, Araya D, Drope J. Illicit cigarette trade in metropolitan Santiago de Chile. Tob Control 2020;29:68-73.

16 Saenz de Miera Juarez B, Reynales-Shigematsu LM, Stoklosa M, et al. Measuring the illicit cigarette market in Mexico: a cross validation of two methodologies. Tob Control 2021;30:125-31.

17 Administración Federal de Ingresos Publicos. Resolución General 2996. Procedimiento. Sistema integral de control, rastreo y localización de productos "TRAFIP". Su implementación. Available: http://servicios.infoleg.gob.ar/infoleglnternet/anexos/ 175000-179999/177362/norma.htm [Accessed 26 Feb 2021].

18 The Economist Intelligence Unit. The global illicit trade environment index. Available: https://www.tracit.org/uploads/1/0/2/2/102238034/eiu_global_illicit_trade_ whitepaper_final.pdf [Accessed 9 Sep 2020].

19 Euromonitor International. Tobacco in Argentina, 2018. Available: https://www. euromonitor.com/tobacco-in-argentina/report [Accessed 7 Nov 2019].

20 Blecher $\mathrm{E}$, Liber $\mathrm{A}$, Ross $\mathrm{H}$, et al. Euromonitor data on the illicit trade in cigarettes. Tob Control 2015;24:100-1.

21 Gallagher AW, Gilmore A. Euromonitor international now accepts tobacco industry funding: a WIN for PMI at the expense of research on the tobacco industry, 2019. Available: https://blogs.bmi.com/tc/2019/04/08/euromonitor-international-now- accepts-tobacco-industry-funding-a-win-for-pmi-at-the-expense-of-research-on-thetobacco-industry/

22 Ramos A. Illegal trade in tobacco in MERCOSUR countries. Trends in Organized Crime 2009:12:267-306

23 Paraje G. Illicit cigarette trade in five South American countries: a gap analysis for Argentina, Brazil, Chile, Colombia, and Peru. Nicotine Tob Res 2019;21:1079-86.

24 Global Youth Tobacco Survey. Factsheet: Argentina, 2018. Available: https://extranet. who.int/ncdsmicrodata/index.php/catalog/761/related_materials [Accessed 26 Feb 2021].

25 González-Rozada M. Economía del control del tabaco en Los países del Mercosur Y Estados Asociados: Argentina: 1996-2004. Washington DC: Pan American Health Organization, 2006.

26 Chernick H, Merriman D. Using littered pack data to estimate cigarette Tax avoidance in NYC. Natl Tax J 2013;66:635-68.

27 Szklo AS, Iglesias RM, Stoklosa M, et al. Cross-Validation of four different survey methods used to estimate illicit cigarette consumption in Brazil. Tob Control 2020. doi:10.1136/tobaccocontrol-2020-056060. [Epub ahead of print: 13 Nov 2020].

28 Instituto Nacional de Estadisticas y Censos. Censo Nacional de Población, Hogares Y Viviendas, 2010. Available: https://www.indec.gob.ar/indec/web/Nivel4-Tema-2-41135 [Accessed 26 May 2020].

29 Administracion Federal de Ingresos Publicos. Resolution 3485. excise taxes: ammendment to general resolution 2445, 2013. Available: https://www.argentina. gob.ar/normativa/nacional/resoluci\%C3\%B3n-3485-2013-211611 [Accessed 7 Nov 2019].

30 Programa de Reconversión de Áreas Tabacaleras del Ministerio de Agroindustria de la Nación. Volumen de Paquetes Vendidos, Evolución Y Rangos de Precios (20082019). Available: https://www.agroindustria.gob.ar/sitio/areas/tabaco/estadisticas/_ archivos//000001-Volumen \%20de\%20Paquetes $\% 20$ de $\% 20$ Cigarrillos $\%$ 20Vendidos\%20por\%20Rango\%20de\%20Precio\%20(2008-2019).pdf [Accessed 11 Nov 2019].

31 EcoCuyo. Jornada sobre venta ilegal, piratería Y fraude marcario en Mendoza, 2017. Available: https://ecocuyo.com/jornada-sobre-venta-ilegal-pirateria-y-fraude-marcarioen-mendoza/ [Accessed 24 Jul 2020].

32 FIC Argentina. Encuesta sobre La conducta Y cambios de hábitos de Los consumidores de tabaco a 12 meses de la implementación de la reforma impositiva en Los productos de tabaco. Available: https://www.ficargentina.org/wp-content/uploads/ 2020/05/2004_encuesta_consumidores.pdf [Accessed 7 Sep 2020].

33 Gomis B, Lee K, Carrillo Botero N, et al. "We think globally": the rise of Paraguay's Tabacalera del Este as a threat to global tobacco control. Global Health 2018;14:110.

34 Philip Morris International. Pmi impact. selected projects: second funding round. Available: https://www.pmi-impact.com/Funding/secondfundinground [Accessed 5 Aug 2020].

35 Gendarmería Nacional Argentina. Informe Público Institucional, 2018. Available: https://prensagendarmeria.gob.ar/descarga/rec/informes/Informe-publicoinstitucional-2018.pdf [Accessed 5 Aug 2020].

36 World Health Organization. Protocol to eliminate illicit trade in tobacco products. Geneva:WHO, 2013.

37 Infobae. Contrabando, drogas Y un acuerdo trabado: La Hidrovía en alerta roja, 2018. Available: https://www.infobae.com/politica/2018/03/05/contrabando-drogas-y-unacuerdo-trabado-la-hidrovia-en-alerta-roja/ [Accessed 30 Jul 2020]. 